\title{
AN EXPERT SYSTEM TO CLASSIFYING AND SCHEDULING OF SERVICE SYSTEMS
}

\section{EDUYN LÓPEZ-SANTANA, GERMAN MÉNDEZ-GIRALDO \& JOSE IGNACIO RODRIGUEZ}

Industrial engineering. Faculty of Engineering. Universidad Distrital Francisco José de Caldas. Bogotá, Colombia

This paper studies the problem of classify scheduling problems in service systems, its performance measures and solution techniques. First, we contribute to classification of service systems that is a difficult task since the service is described in a confused and ambiguous language. This confusion makes it difficult to analyze, mainly in the making decisions at operative level. We propose a new notation for service systems that consist in three fields: customer, resources, and flow control. From this notation, we propose an integrated three rule-based systems. The first identify the type of scheduling problem according with scheduling, routing, and routing-scheduling. With the results a second system identifies the performance measures. And finally, a third system determines the best solution techniques to solve the problem. We develop a computational tool in Java called SchES (Scheduling with Expert Systems) that implements our approach.
\end{abstract}

KEYWORDS: Knowledge Management; Scheduling; Service System; Expert System

Received: Oct 08, 2020; Accepted: Oct 28, 2020; Published: Nov 12, 2020; Paper Id.: IJMPERDOCT202045

\section{INTRODUCTION}

Service systems consist of service providers (resources) and service customers working together to coproduce value (flow control) in complex value networks where providers and customers might be individuals, firms, government agencies, or any organization of people and technologies (E. López-Santana, Méndez-Giraldo, \& Figueroa-García, 2019; E. R. López-Santana \& Méndez-Giraldo, 2016b; Spohrer et al., 2007). Service systems are becoming a strategic area of scientific research from multidisciplinary approaches, such as Service Science or Service Science Management and Engineering (Demirkan, Spohrer, \& Krishna, 2011; Spohrer et al., 2007). In service systems, as the manufacturing systems, there are a decision-making process called scheduling related with the allocation of resources to perform a set of tasks in a specific planning horizon subject several operational constraints such capacity or unavailability of resources, due dates, priorities, cancelations, among others to optimize one or more objectives. This process has applications in computer science, logistic, distribution, production, workforce, maintenance, health systems, among others (E. López-Santana et al., 2019; E. R. LópezSantana \& Méndez-Giraldo, 2016a).

The general scheduling problem consists in finding the best sequence to perform a number of jobsin a number of machines (or resources) in order to optimize a one or more objective functions (Pinedo, 2016). This problem is typically NP-hard and thus is difficult to find an optimal solution since the computation time increases exponentially with the problem size (Pinedo, 2016). The scheduling problems can be classified in deterministic and stochastic problems. In deterministic case, the information about processing times, release date, due dates, 
capacity, among others has a constant value while in stochastic case the information has a stochastic variability (Pinedo, 2016).

The objective of this paper consists inreviewing the problem of scheduling in service systems, where the traditional tools could not be applied directly give the complexity of services. The scheduling in service systems is a decision-making process related with the allocation of resources to perform a set of tasks in a specific planning horizon subject several operational constraints such capacity or unavailability of resources, due dates, priorities, cancelations, among others to optimize one or more objectives (E. R. López-Santana \& Méndez-Giraldo, 2016a). The authors review the scheduling problems in service systems and present a structure of a Knowledge Based System (KBS) to solve it. The proposed KBS by (E. R. López-Santana \& Méndez-Giraldo, 2016a) is supported in two systems. The first one is a service systems classification component (SSCC) applied to International Standard of Industrial Classification (ISIC) system. This result is useful for companies to determine their classification and for entities that consolidate information for statistical purposes. The second one is a task scheduling component (TSC) that allows identifying the scheduling problem (or problems). After, it selects the best solution technique (or techniques) and setting the input data, parameters, outputs, and performance measure to solve the problem.

The remainder of this document is organized as follows. Section 2 presents the proposed notation for service systems. Section 3 shows rule-based system to identify the scheduling problem and suggest a solution technique from the proposed notation. Section 4 presentssome conclusions and future lines of research.

\section{PROPOSED NOTATION FOR A SERVICE SYSTEM}

We propose a notation to represent a service system to identify the scheduling problem and suggest a solution technique. In the literature, there are several notations for scheduling problems. The most popular is the Graham notation provided by (Graham, Lawler, Lenstra, \& Kan, 1979) that consists in a three fields $\alpha|\beta| \gamma . \alpha$ represents the production system's setting, e.g., 1 if is one machine, $\mathrm{F}$ if is a Flow shop problem, $\mathrm{J}$ if is a Job shop problem, among others. $\beta$ is a field where the constraints and characteristics about the jobs and the machines are described, e.g., $r_{i}$ indicates that the jobs have release dates, prmp shows preemptions for the jobs, among others. The last field $\gamma$ represents the performance measure for the scheduling problem, e.g., $C_{\max }$ represent the makespan, $\sum w_{i} C_{i}$ is the total weighted completion times, among others. This notation applies for several scheduling problems mainly in manufacturing environments, however, for the service systems, it lacks the parameter to add characteristics for these systems.

For service systems, the notation used frequently corresponds to the queueing systems that could be characterized in terms of Kendall's notation (Kendall, 1953), whose encoding under the following structure: 1/2/3/4. Where 1 refers to the arrival process that can be Poisson (M), Deterministic (D) or general distribution different to Poisson (G); 2 is the service process that can be also M, D o G; 3 represents the number of servers by stage of process in the network, which can be single (represented by 1 ) or multiple (represented by $s$ ); and 4 states the system's capacity, infinite when it is empty or a $\mathrm{K}$ to indicate the queue's length.

We propose a notation that consists in three fields $C / R / F$, where $C$ is set of parameters related with the customer, $R$ is the set of parameters related with the resources, and $F$ is the set of parameters associated with the flow control. Figure 1 presents our proposed notation over the good-dominant and service-dominant logic views prosed by (Vargo \& Lusch, 2008). In pure manufacturing systems the production and consumption systems are separated, while in pure service system 
both production and consumption systems are related by the interactions and coproduction. Our notation represents this behavior as Flow Control, Figure 2 shows the fields and its groups and variables with the defined outputs for each one. Figure 1 also present some examples of systems for the variable Type of need with its outputs Intangible and Tangible to understand the differences between manufacturing and service systems.

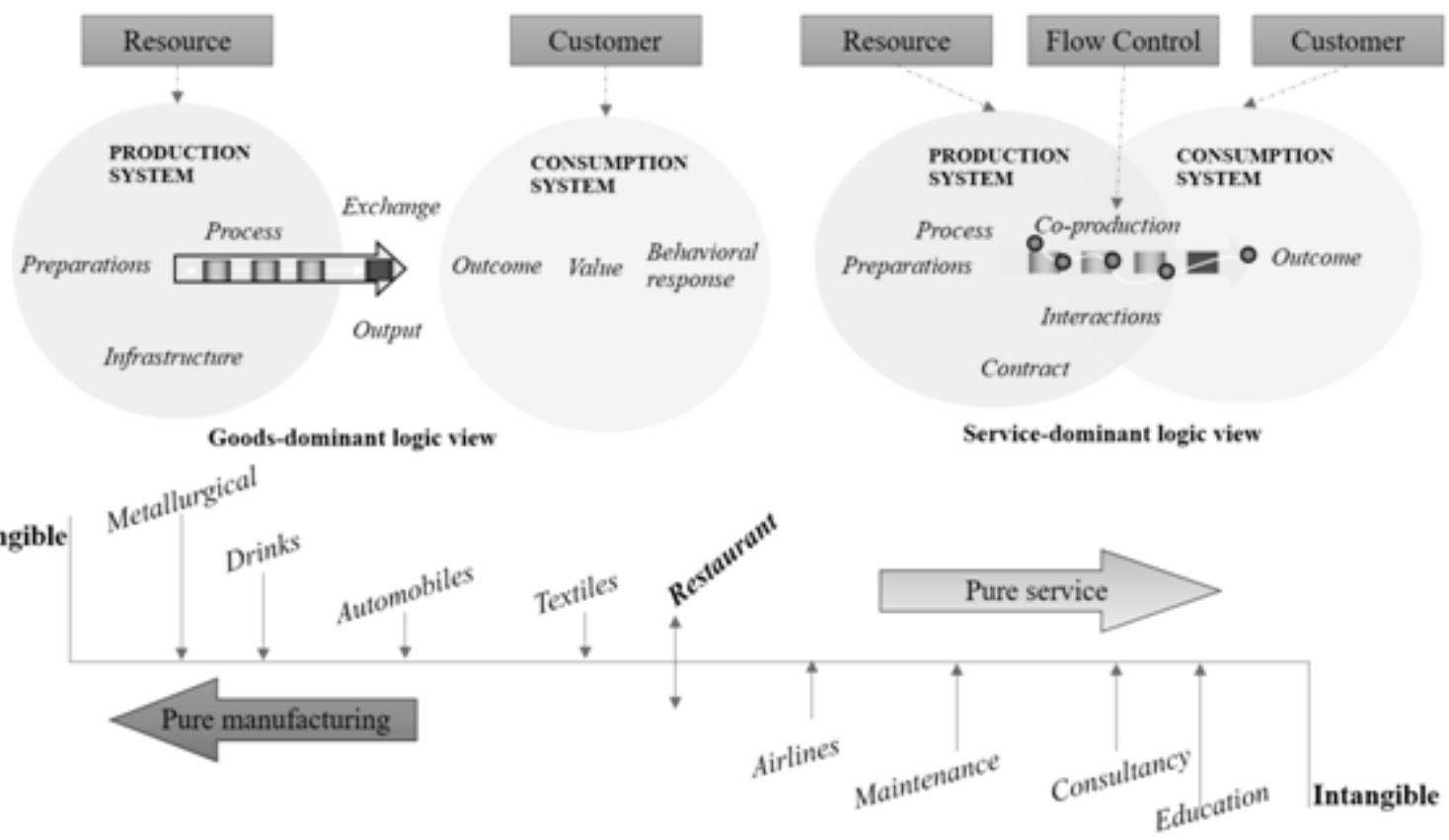

Figure 1: Representation of the proposed notation for manufacturing and service systems
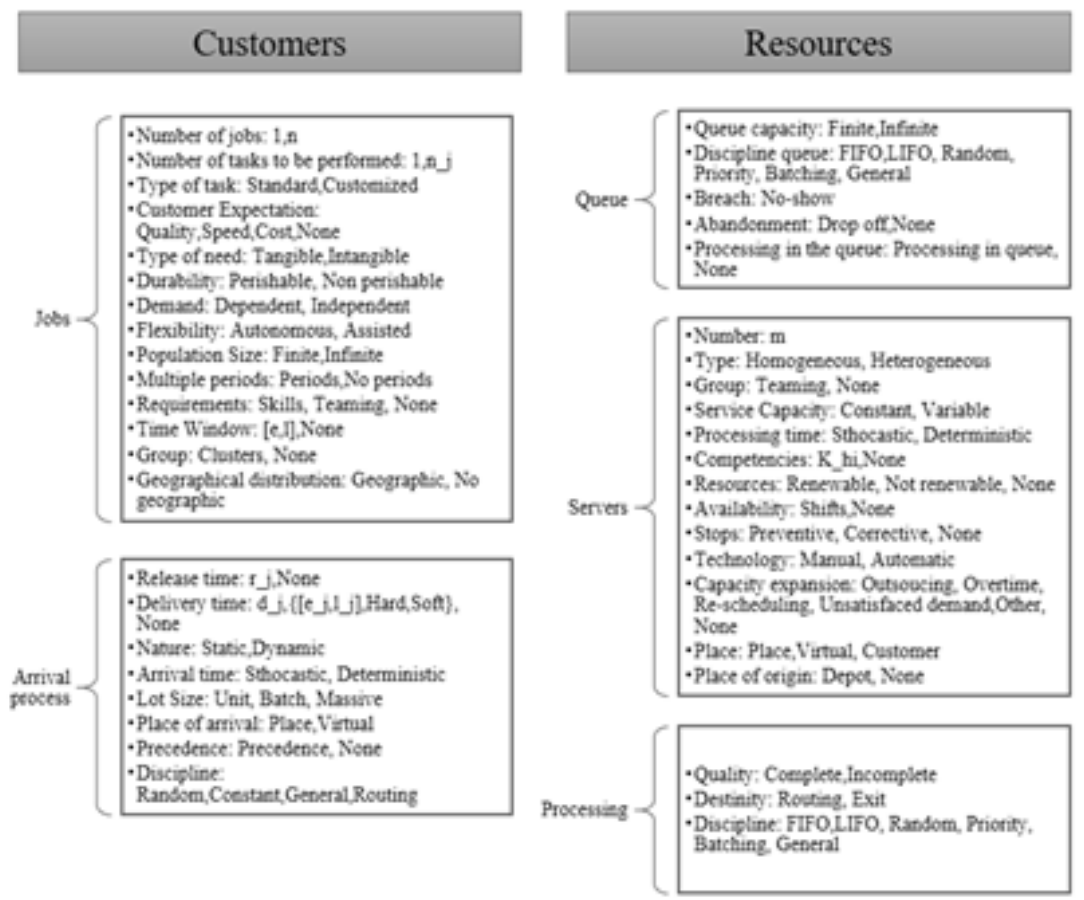

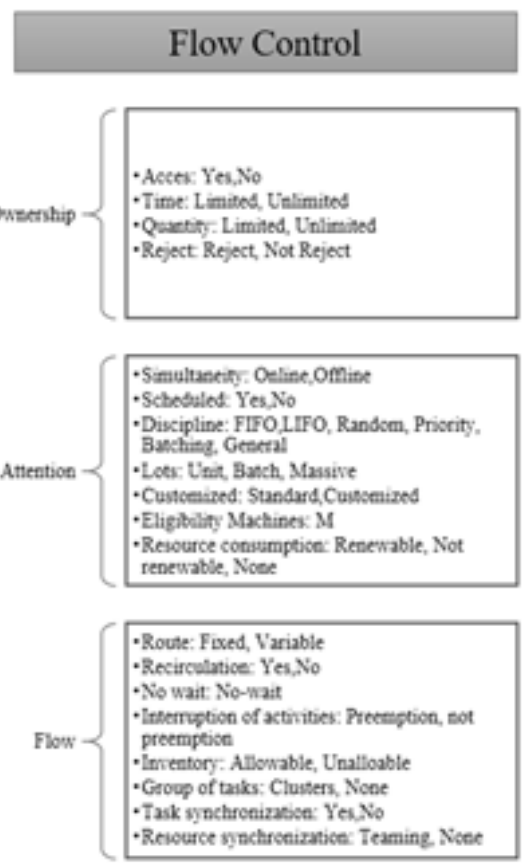

Figure2: Proposed notation for a service system 


\section{PROPOSED RULE-BASED SYSTEM}

López-Santana et. al. (E. R. López-Santana \& Méndez-Giraldo, 2016a) presents a general framework of an knowledge based expert system to solve the scheduling problem in service systems(Lopez-Santana, Castro, \& Giraldo, 2016). Figure 3 shows the framework with two inputs, a service system classification component and the task scheduling component (SSCC) described in (E. R. López-Santana \& Méndez-Giraldo, 2016b) and the task scheduling component (TSC) described here. The SSCC consists in a classification system for the International Standard Industrial Classification (ISIC) system in the Colombian context, also to classify according to economy sector as Services, Manufacturing and Primary proposed by the authors for the section level and division level. Additionally, it is taken as instances for database-level Group, i.e. in total has 249 instances for the selection of rules.

The knowledge base consists in a set of 12 attributes: Coproduction, Dependence, Accumulation, Technology, Property, Simultaneity, Flexibility, Nature, Durability, Place, Scheduled and Standardization. The inference engine was made with an algorithm to generate tree $\mathrm{C} 4.5$ using the entropy information measure. The attributes were modeled using a knowledge acquisition model based in a non-linear optimization and an adaptive neuro-fuzzy inference system (ANFIS) approach (for details see (E. R. López-Santana \& Méndez-Giraldo, 2016b)).

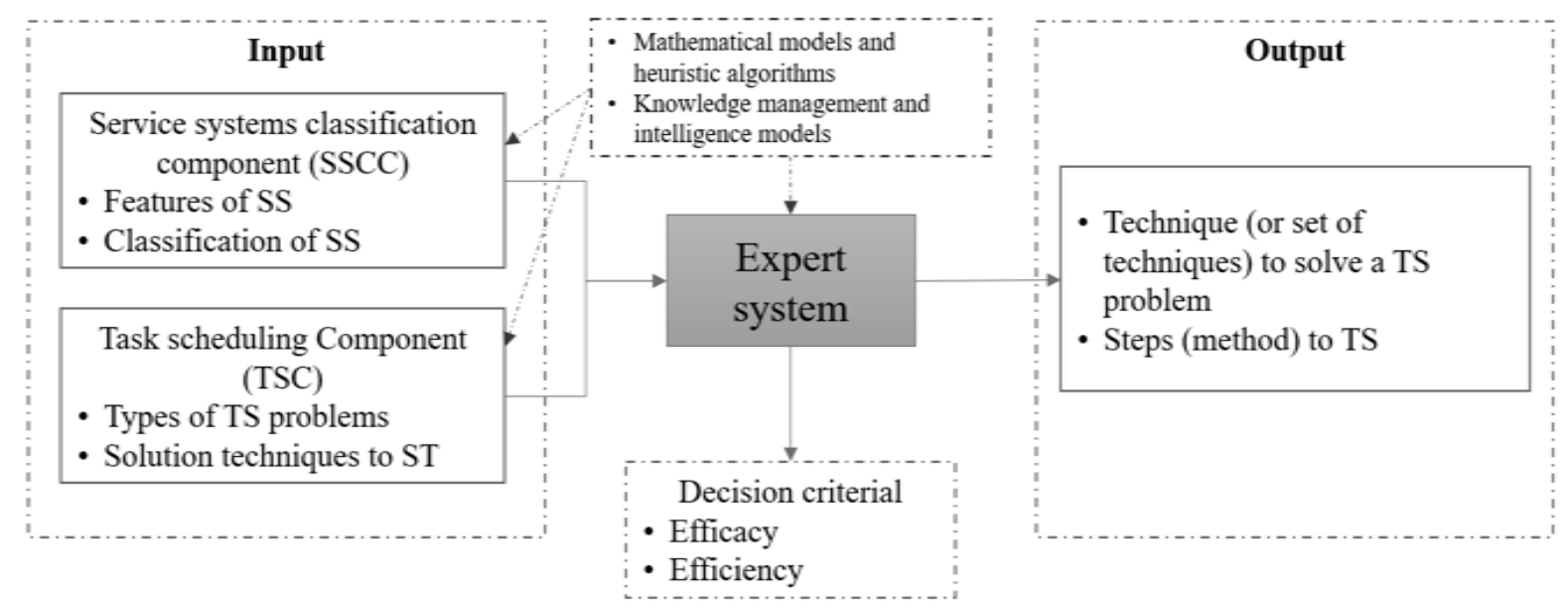

Figure 3: General framework of a KBES to scheduling in service systems (source: (E. R. López-Santana \& MéndezGiraldo, 2016a))

Figure 4 shows the TSC proposed. The TSC consists in a classification system for according with the scheduling problems in services systems. Figure 5 shows the methodology of three phases to build the rule-based system from the general framework of Figure 4. The phase 1 is the knowledge acquisition in order obtain the knowledge base. The knowledge base consists in to determine the set of variables for each field the notation presented in section 2 . We use the set of attributes and characteristics determined by (E. R. López-Santana \& Méndez-Giraldo, 2016b). However, some variables are not related with the attributes or characteristics, then a survey are performed to determine all variables.

The phase 2 uses as inference engine four methods to get the rules: J48 classifier, PART, DecisionTable and DecisionStump. These methods were built in WEKA and the compared with the percentage of correctly classified instances. We have a set of 498 instances to classify with our method (E. López-Santana, 2018). With the results of knowledge base, the inference engine works in waterfall way with three rule-based system (see Figure 4). Firstly, we begin 
with the identification of the scheduling problem for each field of the proposed notation. The output consists in a scheduling problem, a routing problem, or a scheduling \& routing problem. It is possible to obtain the equal problem for all fields or different problems for each field because given the complexity of service systems and according with the notation defined in figures 1 and 2, the customer represents the consumption system, while the resources represents the production system, thus a different scheduling problem could be arise for these subsystems according with (E. López-Santana, 2018) and hence the problem, performance measure and solution technique could be hybrid. However, the analyst of the system could be chosen the same or different according with his/her expertise.

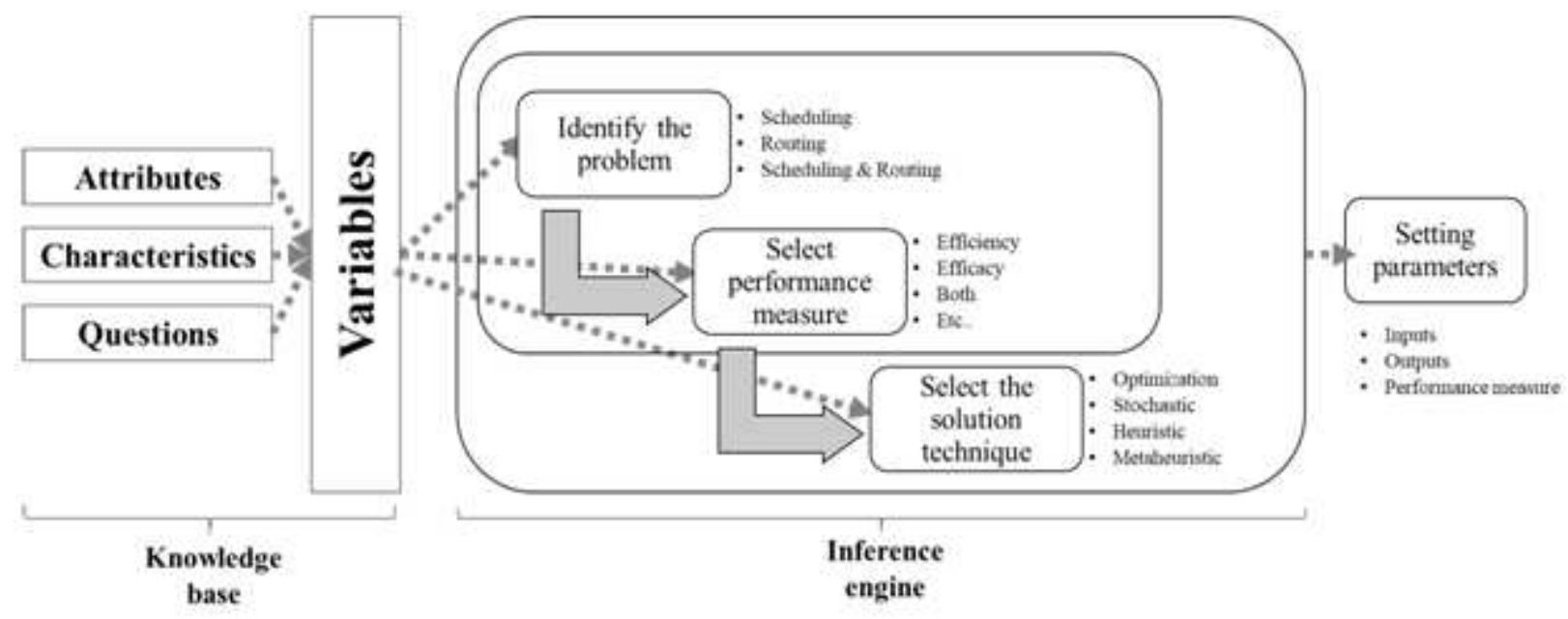

Figure 4: General structure of the proposed rule-based system to scheduling for service systems.

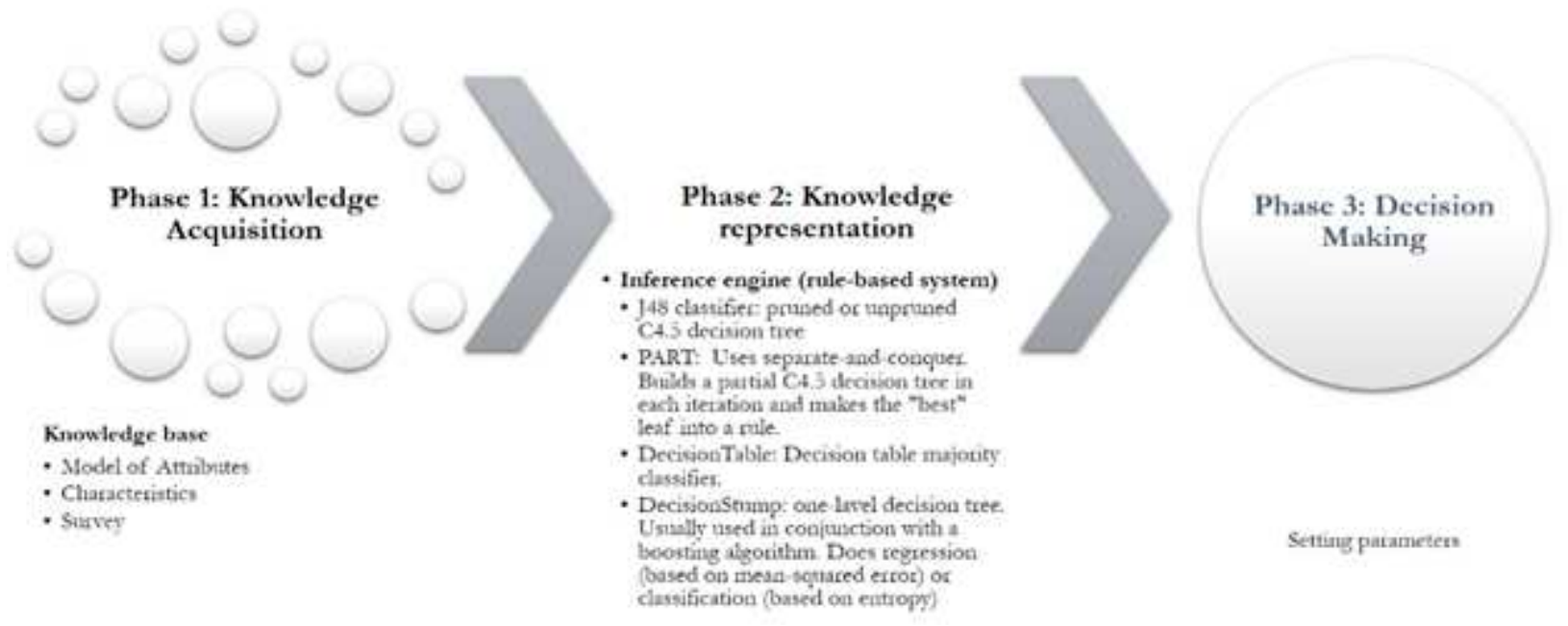

Figure 5: Methodology to build a rule-based system.

Once the problem is determined, we apply the second inference engine to determine the performance measure. For the example, we consider as performance measures a general classification: efficiency, effectiveness, both,and none. Again, the methods are applied for each field and it is possible to get the same or different results for all fields. Finally, with the results of the problem and the performance measure, the third inference engine is applied to determine the solution technique to solve the scheduling problem for each field. For the example, we use four categories of solution techniques: optimization, stochastic models, heuristics, and metaheuristics. Again, the methods are applied for each field and it is 
possible to get the same or different results for all fields.

We develop a computational tool in Java called SchES (Scheduling with Expert Systems) that implements the subsystems described above in an independently way or a together way. Figure 6 presents the designed interfaces for knowledge acquisition and the inference engines. These ones were designed in Java and using Weka We apply our proposed method to a problem proposed in (E. López-Santana, Akhavan-Tabatabaei, Dieulle, Labadie, \& Medaglia, 2016) in order to validate the solution method. The problem consists of planning and scheduling maintenance operations for a set of geographically distributed machines, subject to non-deterministic failures with a set of technicians that perform preventive maintenance and repair operations on the machines at the customer sites within a specific time window.

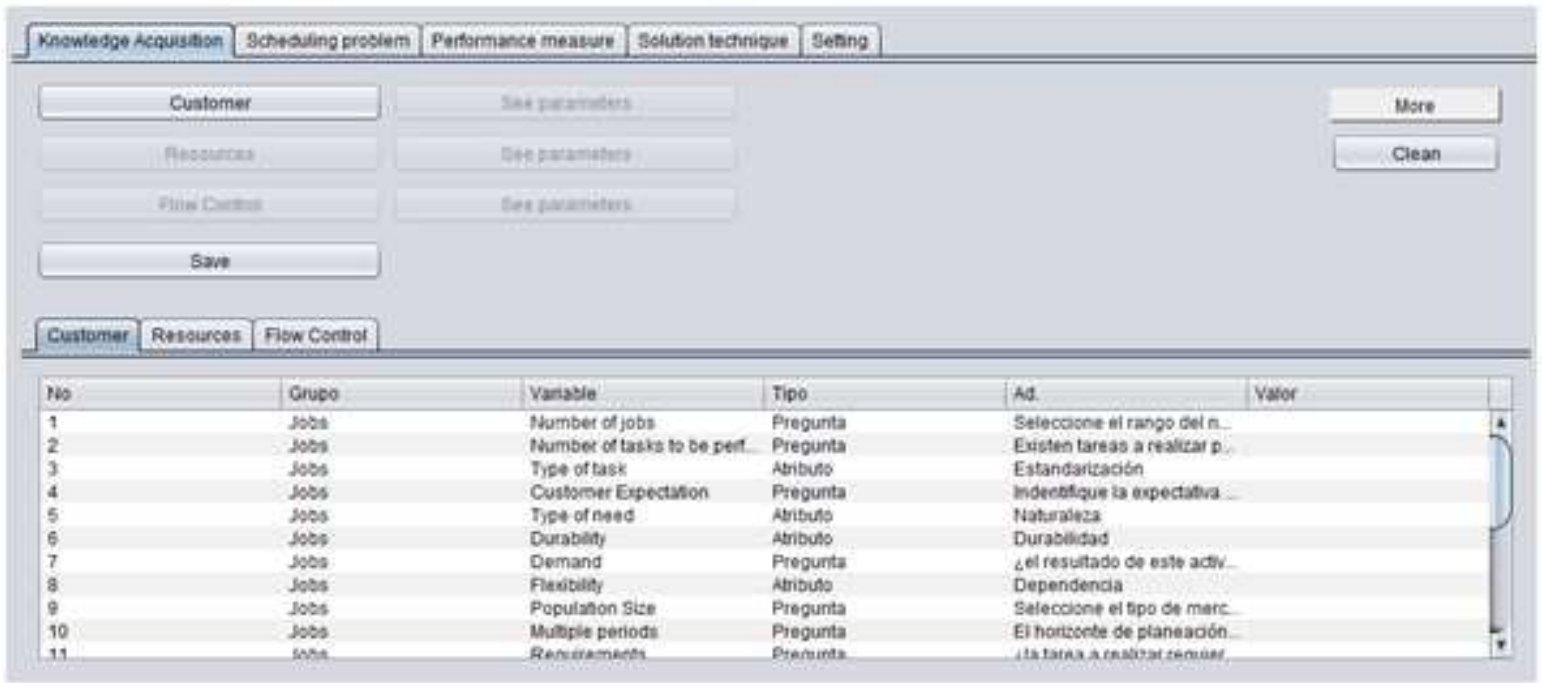

(a)

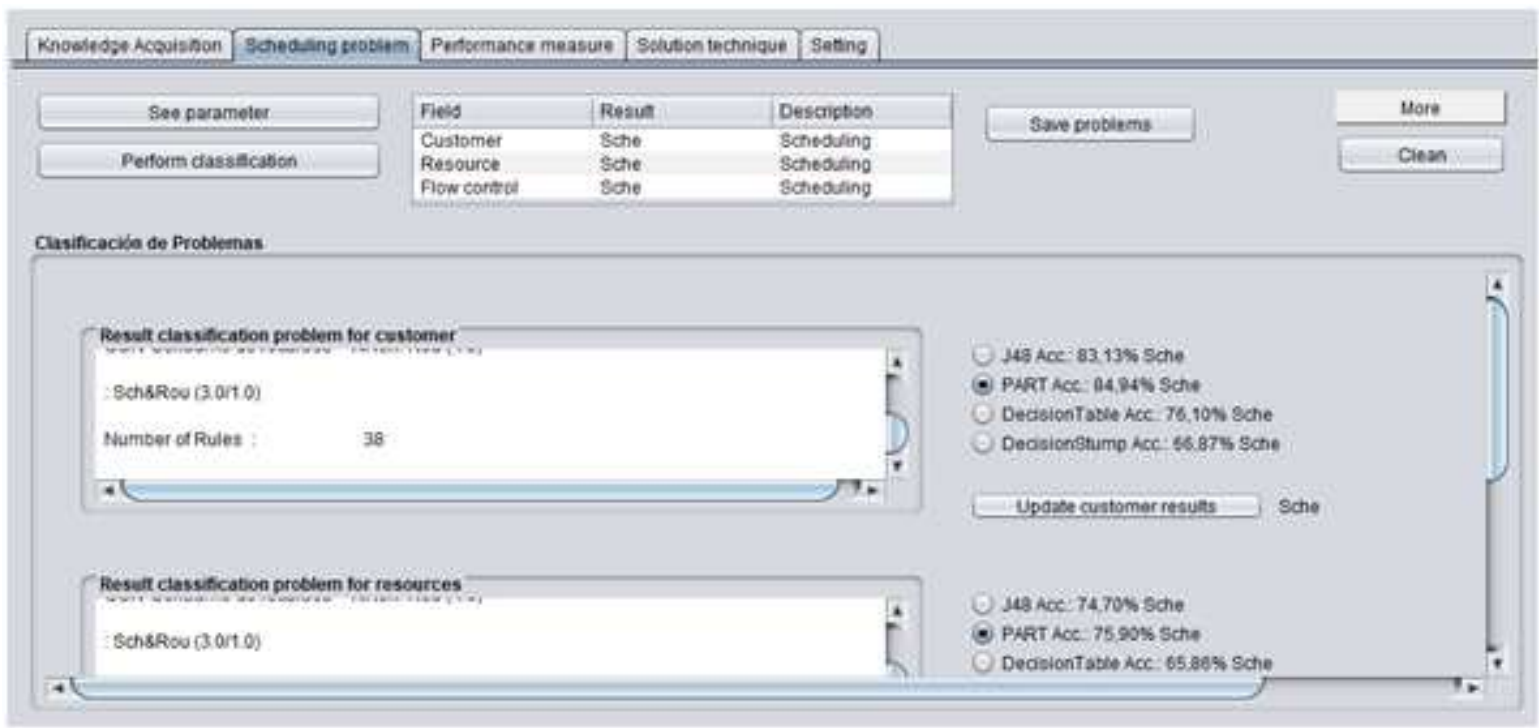

(b)

Figure 6: Interfaces of SchES of (a) knowledge acquisition and (b) scheduling problem classification

\section{CONCLUSIONS}

This paper reviews the scheduling problems in service systems and presents a structure of a rule-based system to identify 
the type of scheduling problem, the performance measure, and the solution technique. We propose a new notation that involves the characteristics of service system in three fields: customers, resources, and flow control. Our notation states a set of variables, which are used as input of the proposed rule-based systems to identify the scheduling problems between a set of options defined as scheduling, routing, or scheduling and routing. Our proposed contribute to the develop of decision support system in the field of give a framework to classify scheduling problems according with a set of characteristics and attributes that involves the major of real features of the service systems. Our proposed, apply several classifiers of the literature, and it is possible to choose other to improve the results.This work generates possible future development lines, one of which is the validation of results with a set of real companies and improving the database of information. Another possible line consists to explore other methods of numerical ratings that involves imprecision, for instance using fuzzy logic.

\section{ACKNOWLEDGEMENTS}

This work was supported in part by the Research center "Centro de Investigaciones y Desarrollo Científico" at Universidad Distrital Francisco José de Caldas (Colombia) under Grant 2-602-468-14.

\section{REFERENCES}

1. Demirkan, H., Spohrer, J. C., \& Krishna, V. (2011). Introduction of the Science of Service Systems. In H. Demirkan, J. C. Spohrer, \& V. Krishna (Eds.), The Science of Service Systems (pp. 1-11). Boston, MA: Springer US. https://doi.org/10.1007/978-1-4419-8270-4_1

2. Graham, R. L., Lawler, E. L., Lenstra, J. K., \& Kan, A. H. G. R. (1979). Optimization and Approximation in Deterministic Sequencing and Scheduling: a Survey. Annals of Discrete Mathematics, 5(C), 287-326. https://doi.org/10.1016/S01675060(08)70356-X

3. Kendall, D. G. (1953). Stochastic Processes Occurring in the Theory of Queues and their Analysis by the Method of the Imbedded Markov Chain. The Annals of Mathematical Statistics, 24(3), 338-354. https://doi.org/10.1214/aoms/1177728975

4. López-Santana, E. (2018). Review of scheduling problems in service systems. Bogotá, Colombia.

5. López-Santana, E., Akhavan-Tabatabaei, R., Dieulle, L., Labadie, N., \& Medaglia, A. L. (2016). On the combined maintenance and routing optimization problem. Reliability Engineering \& System Safety, $145, \quad 199-214$. https://doi.org/10.1016/j.ress.2015.09.016

6. López-Santana, E., Méndez-Giraldo, G., \& Figueroa-García, J. C. (2019). Scheduling in queueing systems and networks using ANFIS. In Studies in Fuzziness and Soft Computing (Vol. 377, pp. 349-372). Springer Verlag. https://doi.org/10.1007/978-3030-10463-4_18

7. Lopez-Santana, E. R., Castro, S. J. B., \& Giraldo, G. A. M. (2016). Modelo metodológico para programación de tareas en sistemas de servicios: un enfoque de ingeniería de software. Redes de Ingeniería, 7(1), 55-66. https://doi.org/10.14483/UDISTRITAL.JOUR.REDES.2016.1.A07

8. López-Santana, E. R., \& Méndez-Giraldo, G. A. (2016a). A Knowledge-Based Expert System for Scheduling in Services Systems. In J. C. Figueroa-García, E. R. López-Santana, \& R. Ferro-Escobar (Eds.), Applied Computer Sciences in Engineering WEA 2016 (Vol. 657, pp. 212-224). Springer International Publishing AG. https://doi.org/10.1007/978-3-31950880-1_19 
9. López-Santana, E. R., \& Méndez-Giraldo, G. A. (2016b). A Non-linear Optimization Model and ANFIS-Based Approach to Knowledge Acquisition to Classify Service Systems. In D.-S. Huang, V. Bevilacqua, \& P. Premaratne (Eds.), Intelligent Computing Methodologies (Vol. 9773, pp. 789-801). Springer International Publishing. https://doi.org/10.1007/978-3-31942297-8_73

10. Pinedo, M. L. (2016). Scheduling: Theory, Algorithms, and Systems. Cham: Springer International Publishing. https://doi.org/10.1007/978-3-319-26580-3

11. Spohrer, J., Maglio, P. P., Bailey, J., Gruhl, D., Jim Spohrer, Paul P. Maglio, ... Daniel Gruhl. (2007). Steps Toward a Science of Service Systems. In The 2007 IEEE International Conference on Information Reuse and (Vol. 40, pp. 71-77). IEEE Computer Society. https://doi.org/10.1109/MC.2007.33

12. Vargo, S. L., \& Lusch, R. F. (2008). Service-dominant logic: Continuing the evolution. Journal of the Academy of Marketing Science, 36(1), 1-10. https://doi.org/10.1007/s11747-007-0069-6 